\title{
NUMERICAL ANALYSIS OF A MODEFID AIRFOIL FOR WIND TURBINE
}

\author{
Wisam Abd Mohammed Al-Shohani \\ Assistant Lecturer, Technical College-Baghdad, Iraq \\ E-mail: wabd1984@yahoo.com \\ (Received: 25/2/2013; Accepted: 13/8/2013)
}

\begin{abstract}
This paper presents a numerical analysis of new airfoil, TCB6612, and compared with respect to standard airfoil NACA4412 using them in wind turbine blade. The main objective of this work is to enhance the aerodynamic performance of airfoil by changing the geometry of the airfoil in order to increase the overall power output of the wind turbine. Two software, GAMBIT and FLUENT, are used in this work; GAMBIT is used to create modeling and meshing of the airfoils while FLUENT is used to simulate and analysis the airfoils. The analysis showed that the significant enhancement in aerodynamic performance for TCB6612 is occurred. It is found that value of $C_{\mathrm{d}} / C_{1}$ is decreased about $10.23 \%$, the power coefficient is reached to $51.9 \%$, and the power output is increased about $9.8 \%$.
\end{abstract}

Keywords: Airfoil, CFD, FLUENT.

\section{1- INTRODUCTION}

The energy of wind has been used for thousands of years. The oldest applications of wind energy include extracting water from wells, making flour out of grain, and other agricultural applications [1]. The first machines utilizing wind energy were operated in the orient. As early as 1,700 B.C., it is mentioned that Hammurabi used windmills for irrigation in the plains of Mesopotamia [2]. In recent times, the use of wind energy has evolved to generation of electricity by wind turbine. The worldwide capacity of generation by wind turbines reached 196,630 Megawatt, out of which 37,642 Megawatt were added in 2010, with growth rate of $23.6 \%$. By the end of year 2020, at least 1,500,000 Megawatt can be expected to be installed globally [3], so the industry of wind turbine is development rapidly. Therefore, the researchers are focusing on increasing the efficiency of generation and decreasing the cost of generation. The aerodynamic performance of wind turbine airfoils was an important foundation for the aerodynamic design and the performance analysis of the wind turbine [4], 
because the power output of wind turbine depends in many parameters and aerodynamic performance of wind turbine airfoils is important one of them.

There have been a many researchers interesting in the investigation, modification, and examination of wind turbine airfoil. Qu et al. [5] conducted the performance influence of maximum thickness position on vertical axis wind turbine airfoil. NACA0015 airfoil was chosen as the basic airfoil, whose maximum thickness position was shifted to generate another four airfoils, with using XFLR5 program. They found that maximum thickness position has important impact on the airfoil performance. With the change of Reynolds number, shifting the maximum thickness position has varying degrees of effects on airfoil aerodynamic characteristics.

Limin et al. [6] proposed new airfoil for the small wind turbine based on the seagull airfoil and compared the new airfoil with NACA 4412 airfoil by using the CFD software. The analyses show that the airfoil of the seagull is suitable for the special work circumstances of the small wind turbine and can be used for the design of the blades, especially in the tip.

Beri and Yao [7] studied the effect of modified airfoil at the trailing edge on self-starting of vertical axis wind turbine based on the computational fluid dynamic analysis using FLUENT software. The model was created with airfoil modified from conventional NACA0018 to be flexible at $15^{\circ}$ from the blade axis at the trailing edge located about $70 \%$ of the blade chord length. The simulation results were then compared to cambered airfoil NACA2415 which is self-starting. The simulation result shows that the modified airfoil has better self-starting performance for the modeled turbine.

Henriques et al. [8] presented the design methodology of a new wind turbine airfoil that achieves high performance in urban environment by increasing the maximum lift. For this purpose, an inverse method was applied to obtain a new wind turbine blade section with constant pressure-load along the chord, at the design inlet angle. In comparison with conventional blade section designs, The results show that the new airfoil has increased maximum lift, reduced leading edge suction peak and controlled soft-stall behavior, due to a reduction the pressure distribution of the designed blade section shows a smooth increase of the blade pressure-load, defined as the pressure difference between the upper and the lower sides of the section, from the leading edge up to $20 \%$ of the axial chord. From $20 \%$ up to $80 \%$ of the axial chord, pressure-load is almost constant and it reduces smoothly toward the trailing edge.

Gharali and Johnson [9] simulated numerically of an S809 airfoil using a commercial CFD package, ANSYS FLUENT. The resultant aerodynamic coefficients presenting dynamic stall phenomena are compared with aerodynamic coefficients from existing experimental and semi-empirical data for a pitch oscillating S809 airfoil. The results show that a decreasing lift 
coefficient depends on the thickness of the erosion rather than the length of the erosion. Erosion of the leading edge changes the standard shape of the airfoil and when significant erosion occurs the characteristics of the dynamic stall phenomena based on the smooth S809 can no longer be predicted. The average (maximum) lift decrease has reached $34 \%$ for the thickest erosion assumption.

Beri and Yao [10] proposed NACA0018 airfoil to be open able at low tip speed ratio to work as drag device and then be closed to take the normal blade geometry of the airfoil at higher tip speed ratios to work as lift device. A computational fluid dynamic solver FLUENT used to analyze the airfoil. The simulation result shows that the generations of negative torque increases with the increase of opening angles and vice versa.

Rajakumar and Ravindran [11] presented an approach for the determination of aerodynamic performance characteristics of horizontal-axis wind turbines. The airfoils NACA 4410 and NACA 2415 are taken into consideration for evaluating this proposed approach using the CFD analysis. For that, GAMBIT is used to create modeling and meshing of airfoil and exported to FLUENT for analysis. Also, the work focus on CFD analysis of a wind turbine blade. The results are presented the effect of dimensionless lift coefficient $\left(C_{L}\right)$, drag coefficient $\left(C_{D}\right)$ and pressure coefficient at different angle of attack.

Song and Keane [12] studied the parameterisation methods for airfoil shape optimization within a CAD-based design optimisation framework. In their work, three datum airfoils, two from the NACA supercritical airfoils family (NACA0406 and NACA0610) and the third being the RAE2822, are used as reference shapes to compare different parameterization methods for airfoil design. They found that the B-spline approach produces better results in terms of accuracy at a higher computational cost while the basis function approach is more efficient while producing less accurate results.

Singh et al. [13] presented the design and parameters associated with blade geometry of a new airfoil developed for small horizontal axis wind turbines. A CFD analysis was performed on the improved airfoil (AF300). The airfoil showed good aerodynamic performance attaining the highest combinations of optimum $\mathrm{C}_{\mathrm{L}}$ and $\mathrm{L} / \mathrm{D}$ ratios.

Yao et al. [4] studied the numerical simulation of aerodynamic performance for dimensional wind turbine airfoil. NACA0018 airfoil which developed by U.S. National Aviation Advisory Board was analyzed numerically, and the lift and drag coefficient of the airfoil under different turbulence models were discussed.

The studies in above have simulated many types of airfoil using the CFD analysis with different results. The scope of the work described in this paper was focused on developing geometry of four digit airfoil specifically. For that, an investigation of a new airfoil TCB 6612 which developed in Technical Collage-Baghdad TCB is analyzed and compared with a 
conventional airfoil NACA4412 using a CFD package, FLUENT software, while the GAMBIT software is used to create modeling and meshing of airfoils. Also, the coefficient of power and power output of the wind turbine are calculated by using the two airfoils.

\section{2- POWER OF WIND ROTOR:}

The power generated by the rotor is calculated according to the blade element momentum theory. This theory was proposed by Froude and Taylor. In this approach it is considered that the blades are made up of a number of strips arranged in the span wise direction. The strips have infinitesimal thickness. These strips are aerodynamically independent and do not have any interference between them. Under this analysis, the lift and drag forces acting over the strip are estimated and integrated over the total blade span incorporating the velocity terms, to obtain the torque and power developed by the blade. This is further multiplied by the number of blades to get the total rotor torque and power [14].

Mathematically, the amount of power captured by the rotor is depends on the density of air, area of rotor, velocity of wind, and the rotor power coefficient. Therefore, the power captured by the rotor $P$ may be expressed as [15]

$\mathrm{P}=\frac{1}{2} \rho A V^{3} \mathrm{C}_{\mathrm{P}}$

Where $\rho$ is the air density (in $\mathrm{kg} / \mathrm{m}^{3}$ ), $A$ is the area of the rotor (in $\mathrm{m}^{2}$ ), $V$ is the wind velocity (in $\mathrm{m} / \mathrm{s}$ ), and $C_{P}$ is rotor power coefficient (dimensionless).

and the power coefficient is given by:

$C_{P}=\left(8 / \lambda^{2}\right) \int_{\lambda_{h}}^{\lambda} \sin ^{2} \varphi\left(\cos \varphi-\lambda_{r} \sin \varphi\right)\left(\sin \varphi+\lambda_{r} \cos \varphi\right)\left[1-\left(C_{d} / C_{l}\right) \cot \varphi\right] \lambda_{r}^{2} d \lambda_{r}$

where $\lambda$ is the tip speed ratio, $\lambda_{r}$ is the local tip speed ratio, $\lambda_{h}$ is the tip speed ratio at the hub, $\varphi$ is angle of attack, $C_{d}$ is drag coefficient, and $C_{l}$ is lift coefficient.

The tip speed ratio, $\lambda$, defined as the ratio of the blade tip speed to the free stream wind speed, is given by:

$\lambda=\frac{\Omega \mathrm{R}}{\mathrm{V}}$

Where $\Omega$ is the angular velocity of the wind turbine rotor (in radians/sec), and $R$ is the radius of the wind rotor (in $\mathrm{m}$ ).

The local speed ratio, $\lambda_{r}$, is the ratio of the rotor speed at some intermediate radius to the wind speed:

$\lambda_{\mathrm{r}}=\frac{\Omega r}{\mathrm{~V}}$ 
It's clear from the equation (2) that the coefficient of wind rotor dependent upon several parameters, from these parameters, the magnitude of the coefficient of $\operatorname{drag}\left(C_{d}\right)$ and coefficient of lift $\left(C_{l}\right)$. This, in turn, depends on the aerofoil profile. Data on drag and lift coefficients at different angles of attack may be available for standard airfoil sections. As we would like to minimize the drag force and maximize the lift force, corresponding to minimum $C_{d} / \mathrm{C}_{l}$ is to be identified [14]. In this paper, the $C_{d}$ and $C_{l}$ values of the new airfoil TCB6612 obtained by CFD approached using FLUNT in order to find the maximum $C_{l}$ and minimum $C_{d}$

\section{3- AERODYNAMICS OF AIRFOIL:}

The cross-section of a wind turbine blade is an airfoil [1]. Airfoils are structures with specific geometric shapes that are used to generate mechanical forces due to the relative motion of the airfoil and a surrounding fluid. Wind turbine blades use airfoils to develop mechanical power. The width and length of the blade are functions of the desired aerodynamic performance, the maximum desired rotor power, the assumed airfoil properties, and strength considerations [16].

A number of terms are used to characterize an airfoil, which are defined by the American NACA (National Advisory Committee for Aeronautics) airfoil as shown in Figure (1). The airfoil parameters are [17]:

- Chord length $c$

- Maximum camber $f$ or camber ratio $(f / c)$ in percent, as max. curvature over the median line

- Position of maximum camber $x_{f}$

- Maximum airfoil thickness $d$, as largest diameter of the inscribed circles with their centers on the mean camber line, or thickness-to-chord ratio $(\mathrm{d} / \mathrm{c})$ in percent

- Position of maximum thickness $x_{d}$

- $\quad$ Nose radius $r_{\mathrm{N}}$

- $\quad$ Airfoil co-ordinates $z_{\mathrm{u}}(x)$ and $z_{\mathrm{l}}(x)$ of the upper and lower side contours

The most important airfoil families are Four-digit NACA airfoils:

- 1st digit: maximum camber-to-chord ratio in percent

- 2nd digit: camber position in tenths of the chord length

- 3rd/4th digit: maximum thickness-to-chord ratio in percent

For example NACA 4412 manes that $4 \%$ camber-to-chord ratio at $40 \%$ of the chord length, maximum thickness- to-chord ratio of $12 \%$, and the thickness position of all four- 
digit airfoils amounts to $30 \%$ of the chord length. In TCB6612, the $6 \%$ camber-to-chord ratio at $60 \%$ of the chord length, maximum thickness- to-chord ratio of 12 .

\section{4- NUMERICAL SIMULATION}

Two airfoil is simulated in this paper, NACA4412 airfoil which developed by American NACA (National Advisory Committee for Aeronautics) was selected as a reference airfoil, and TCB6612 airfoil which is proposed in this paper in order to enhanced the performance of the airfoil. The geometry of NACA4412 and TCB6612 which chord length of 1m are shown in Figure (2).

Numerical simulation parameters of airfoil determined by the Reynolds number $R e$ :

$R e=\frac{\rho V L}{\mu}$

Where $\rho$ is air density, $\mu$ is the fluid dynamic viscosity coefficient, $L$ is airfoil's chord length, and $V$ is the relative speed between airfoil and flow. The numerical simulation parameters value presented in Table 1 used in calculation [4].

The computational domain was composed of front half of semicircle and the back half of rectangle which the radius of semicircle was $16 \mathrm{~m}$ and the side length of rectangle was $32 \mathrm{~m}$ and 30m relatively, airfoil was located near the center of semicircle. [4], in mesh, using a $\mathrm{C}$ grid layout; different cell sizes for a quadratic mesh have been used to make the aerodynamic forces independent of the grid size [9]. The mesh contained 150,000 cells were distributed with high resolution on the leading and trailing edges as shown in Figure (3-4).

For the boundary conditions, Inlet velocity for the experiments and simulations is 10 $\mathrm{m} / \mathrm{sec}$ and turbulence viscosity ratio is 10 , outlet boundary was set as pressure-outlet, and airfoil surface was set as adiabatic no-slip wall [4,11]. A fully two dimensional, turbulent flow solution was used in FLUENT, where Spalart - Allmaras model was used for turbulent viscosity [11]. To ensure the reliability of the numerical simulations performed in this analysis, a validation process is carried out. The airfoil used for the validation is the GA (W)$1[18]$

\section{RESULTS AND DISCUSSION}

The airfoils with different shapes and sizes had different lift and drag force, so nondimensional lift coefficient and drag coefficient were used usually to explore the pros and cons of airfoils [4]. The Figures (4) and (5) show the results of lift coefficient and drag coefficient for NACA4412 and TCB6612, respectively, which are carried out by FLUENT. According to Figure (4), the results show that the lift coefficient of the NACA4412 is 
0.55645 while the lift coefficient of the TCB6612 is 0.6550 . From these results, it can be found that the value of lift coefficient is increased about 17.7\%. Figure (5) shows the drag coefficient of the NACA4412 is 0.00095 while the drag coefficient of TCB6612 is 0.001 . From these results, it can be found that the value of drag coefficient is increased about $5.26 \%$. Therefore, the $C_{\mathrm{d}} / C_{1}$ of the NACA4412 and TCB6612 is $1.7 \times 10^{-3}$ and $1.526 \times 10^{-3}$, respectively. It can be found that the value of $C_{\mathrm{d}} / C_{1}$ is decreased about $10.23 \%$

The relationship between the power coefficient $\left(C_{\mathrm{p}}\right)$ and the tip speed ratio $(\lambda)$ for a wind turbine rotor using two airfoils, NACA4412 and TCB6612, is calculated by equations (2-5). This relationship was showed in Figure (6). It is clear from the figure that the maximum power coefficient for wind turbine rotor with NACA4412 and TCB6612 occurs when the tip speed ratio is equal to 7 . The maximum power coefficient of the wind turbine rotor with NACA4412 and TCB6612 is equal to $47.25 \%$ and $51.9 \%$, respectively.

The power output of wind turbine is calculated by equation (1). The Figure (7) shows the results of power output of wind turbine with $5 \mathrm{~m}$ diameter of rotor using NACA4412 and TCB6612 airfoils. The results show the power output of the wind turbine using TCB6612 airfoil is greater than wind turbine using NACA4412 airfoil about $9.8 \%$.

\section{5- CONCLUSIONS}

In this paper, the numerical simulation by CFD using FLUENT software was used to analyzing two airfoils. One of this airfoil is a standard airfoil NACA4412, and another airfoil is a new airfoil TCB6612. The new airfoil is proposed in order to increasing the aerodynamic performance by enhanced on the geometry of airfoil. The results of this study was showed significant enhancements in aerodynamic performance of the airfoil which was effect directly on the overall power output of the wind turbine. Also, it can be conclude that the new airfoil parameters are relatively better than standard airfoil, and the power output of the wind turbine is affected significantly. These results are a reference for further research which can be taken out the experimental test for small wind turbine with TCB6612 by using wind tunnel. 


\section{REFERENCES}

[1] Pramod Jain. Wind Energy Engineering. McGraw-Hill, New York 2011. pp. 1, 41.

[2] Robert Gasch, Jochen Twele. Wind Power Plants - Fundamentals, Design, Construction and Operation, Second Edition. Springer, Berlin 2012. pp. 15.

[3] World Wind Energy Report. World Wind Energy Association, Boon, 2010.

[4] Ji Yao, Weibin Yuan, jianliang Wang, Jianbin Xie, Haipeng Zhou , Mingjun Peng, Yong Sun. Numerical simulation of aerodynamic performance for two dimensional wind turbine airfoils. Procedia Engineering 31 (2012) 80-86.

[5] Jianjun Qu, Yi Mei, Mingwei Xu. Investigation on performance influence of maximum Thickness position on vertical axis wind turbine Airfoil. Power and Energy Engineering Conference (APPEEC), 2011 Asia-Pacific

[6] Qiao Limin, Wei Sidong, Gu Rui, Quan Xiaolin, Yang Yingjun. The investigation of the airfoil for the small wind turbine based on the seagull airfoil. Power and Energy Engineering Conference (APPEEC), 2011 Asia-Pacific

[7] Habtamu Beri, Yingxue You. Numerical simulation of unsteady flow to show self-starting of vertical turbine using fluent. Journal of Applied Sciences 11 (6): 962-970, 2011

[8] J.C.C. Henriques, F. Marques da Silva, A.I. Estanqueiro, L.M.C. Gato. Design of a new urban wind turbine airfoil using a pressure-load inverse method. Renewable Energy 34 (2009) 2728-2734

[9] Kobra Gharali, David A. Johnson. Numerical modeling of an S809 airfoil under dynamic stall, erosion and high reduced frequencies. Applied Energy 93 (2012) 45-52

[10] Habtamu Beri, Yingxue Yao. Computational Analysis of Vertical Axis Wind Turbine with open-able airfoil, Power and Energy Engineering Conference (APPEEC), 2011 AsiaPacific

[11] S. Rajakumar, D. Ravindran. Iterative approach for optimising coefficient of power, coefficient of lift and drag of wind turbine rotor. Renewable Energy 38 (2012) 83-93

[12] Wenbin Song Andrew J. Keane. A Study of Shape Parameterisation Methods for Airfoil Optimisation. 10th AIAA/ISSMO Multidisciplinary Analysis and Optimization Conference, Albany, New York, Aug. 30-1, 2004

[13] Ronit K. Singh, M. Rafiuddin Ahmed, Mohammad Asid Zullah, Young-Ho Lee. Design of a low Reynolds number airfoil for small horizontal axis wind turbines. Renewable Energy $42(2012) 66-76$

[14] Sathyajith Mathew. Wind Energy Fundamentals, Resource, Analysis and Economics. Springer, Berlin, 2006: 31, 36. 
[15] Yasuhito Nakatake, Hiroshi Tanaka. A new maritime lifesaving distiller driven by wind. Desalination 177 (2005) 31-42

[16] J. F. Manwell, J. G. McGowan, A. L. Rogers. Wind Energy Explained - Theory, Design, and Application, Second Edition. Wiley, UK, 2009: 101

[17] Erich Hau. Wind Turbines - Fundamentals, Technologies, Applications, Economics, Second Edition. Springer, Berlin, 2006: 132

[18] A.F.P. Ribeiro ^, A.M. Awruch, H.M. Gomes. An airfoil optimization technique for wind turbines. Applied Mathematical Modelling 36 (2012) 4898-4907 


\begin{tabular}{|c|c|}
\hline \multicolumn{2}{|l|}{ LIST OF ABBREVIATIONS } \\
\hline$A$ & Area of rotor $\left(\mathrm{m}^{2}\right)$ \\
\hline$C_{d}$ & Drag coefficient (-) \\
\hline$C_{l}$ & Lift coefficient (-) \\
\hline$C p$ & Rotor power coefficient (-) \\
\hline$L$ & airfoil's chord length (m) \\
\hline$P$ & Power captured by the rotor (W) \\
\hline$V$ & Wind velocity (m/s) \\
\hline$\mu$ & fluid dynamic viscosity coefficient (kg/m.s) \\
\hline$\lambda$ & Tip speed ratio (-) \\
\hline$\lambda_{h}$ & Tip speed raio at the hub (-) \\
\hline$\lambda_{r}$ & Local tip speed ratio (-) \\
\hline$\rho$ & Air density (kg/m) \\
\hline$\Phi$ & Angle of attack (deg.) \\
\hline$\Omega$ & Angular velocity (rad/s) \\
\hline
\end{tabular}

Table (1): Numerical simulation parameters data [4]

\begin{tabular}{|c|c|c|}
\hline Parameter & Value & Unit \\
\hline Air density, $\rho$ & 1.225 & {$[\mathrm{~kg} / \mathrm{m}]$} \\
\hline fluid dynamic viscosity coefficient, $\mu$ & $1.7894 \times 10^{-5}$ & {$[\mathrm{~kg} /(\mathrm{m} . \mathrm{s})]$} \\
\hline Chord length, 1 & 1 & {$[\mathrm{~m}]$} \\
\hline Relative Mach number & 0.023 & - \\
\hline Angle of attack, $\varphi$ & 13 & {$[\mathrm{deg}]$} \\
\hline Reynolds number & $5 \times 10^{5}$ & - \\
\hline
\end{tabular}




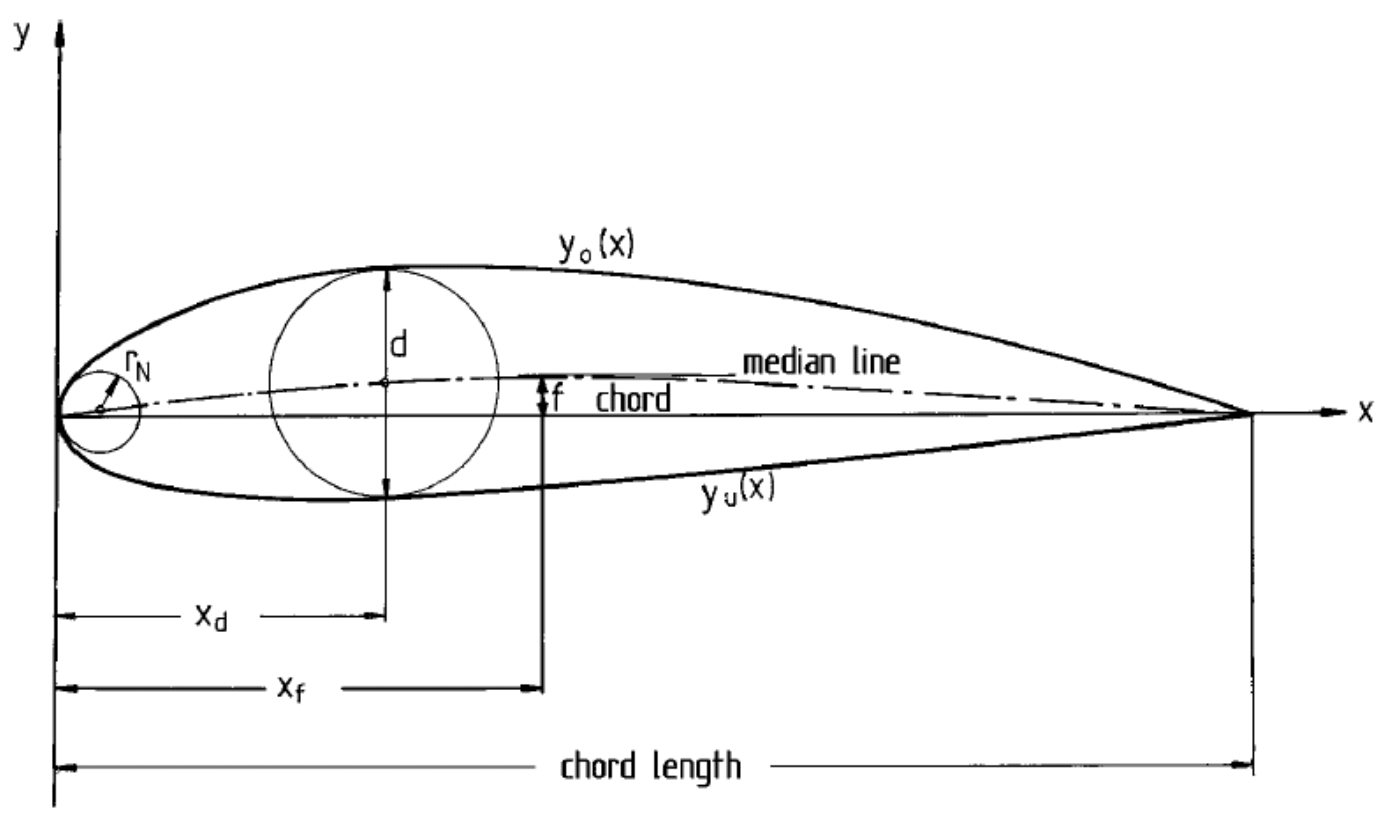

Figure (1): Geometric airfoil parameters of the NACA airfoil series [17]

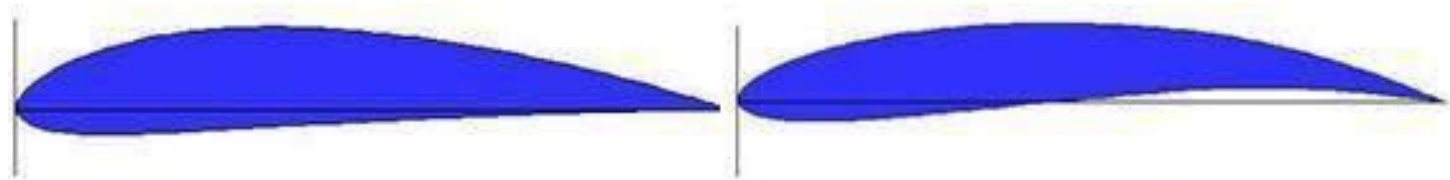

Figure (2): Geometry of NACA4412 airfoil (left) and TCB6612 airfoil (right).

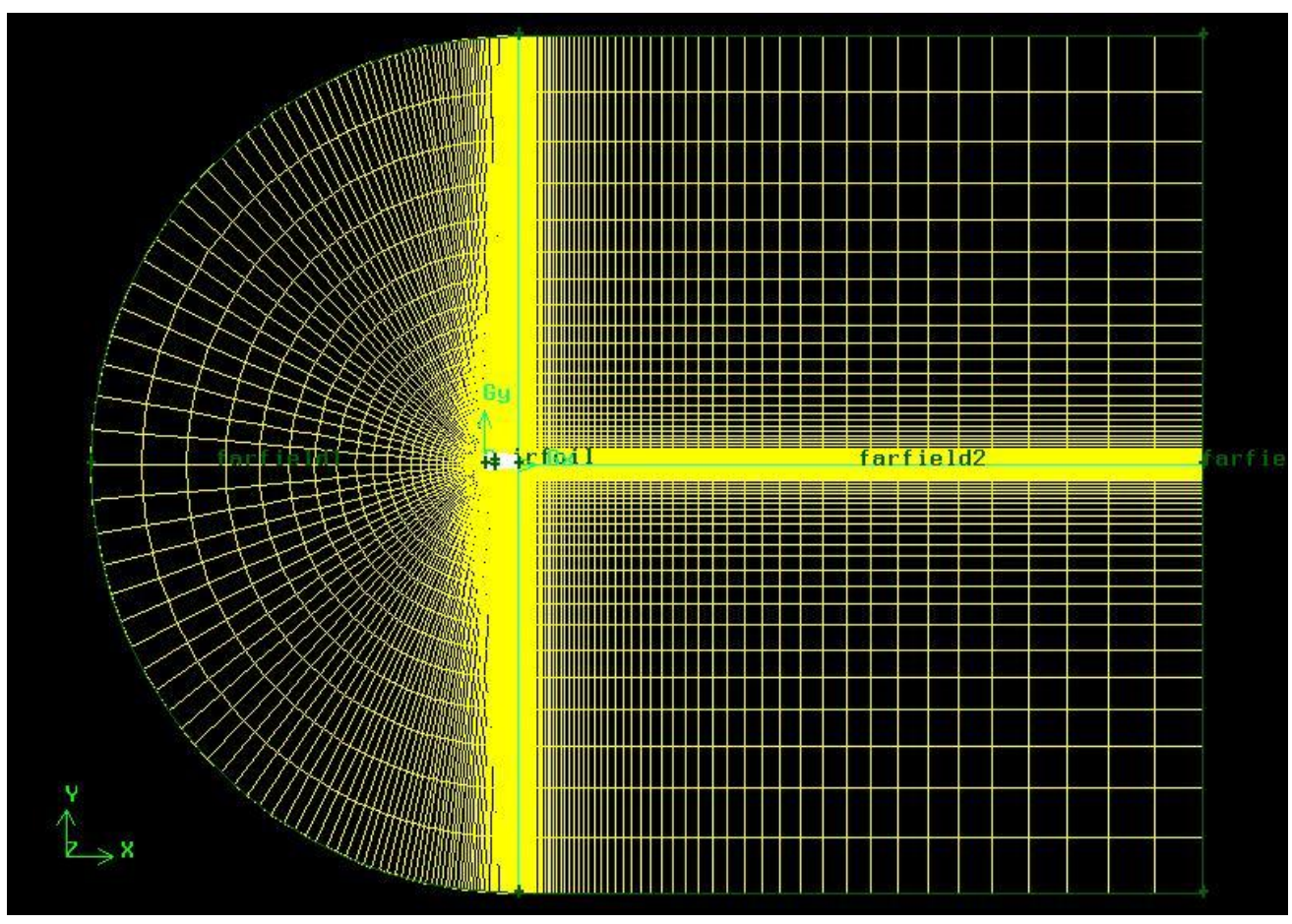

Figure (3): Mesh of the computational domain by GAMBIT. 


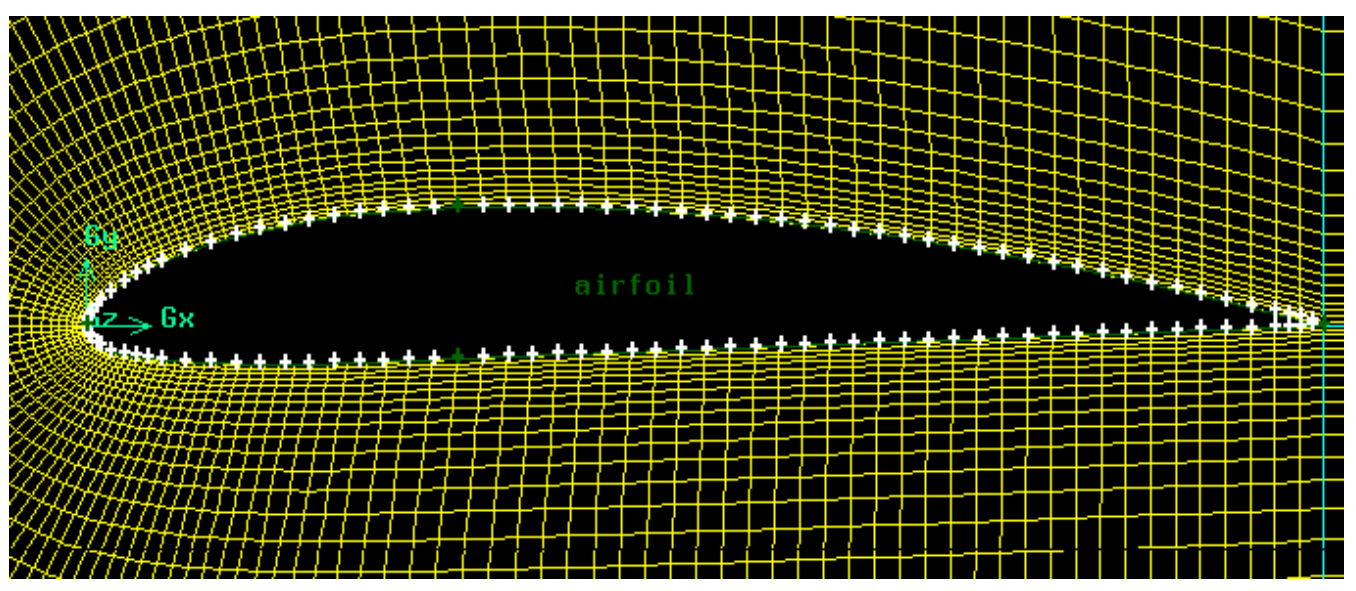

Figure (4): Close-up look at the mesh around the airfoil.

NACA4412

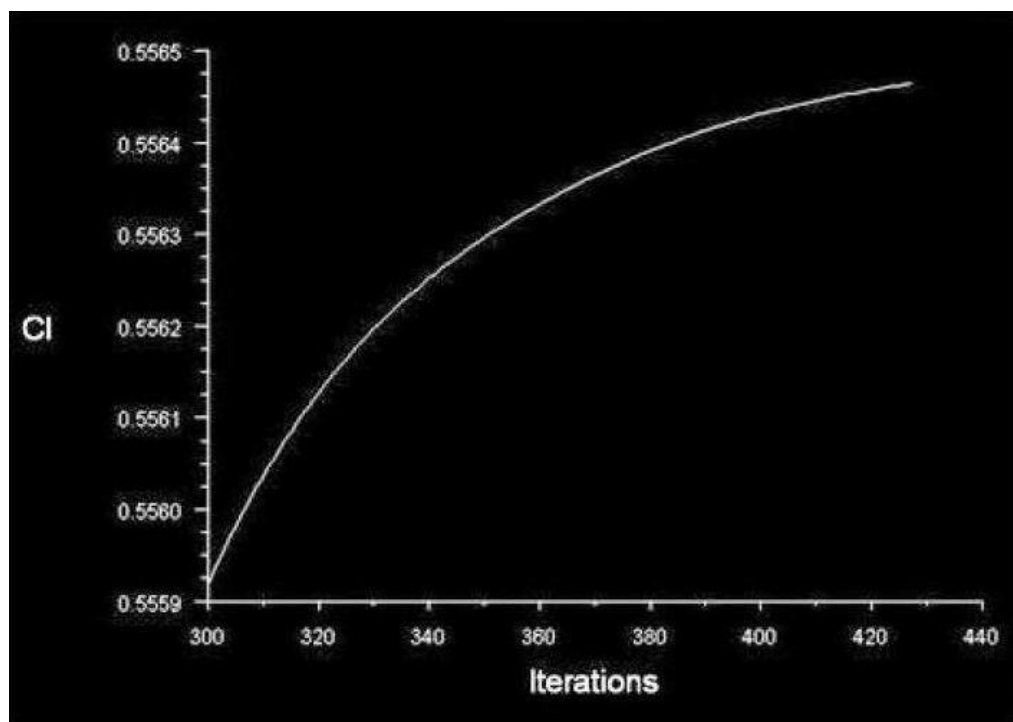

TCB6612

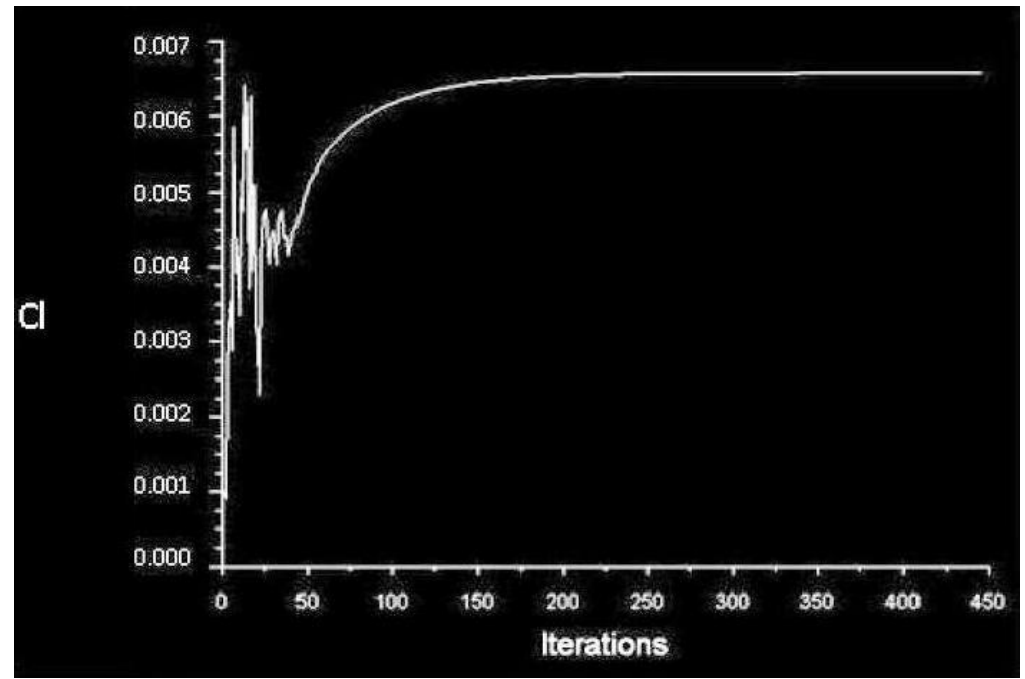

Figure (5): Lift Coefficient of NACA 4412 airfoil and TCB6612 airfoil. 
NACA4412

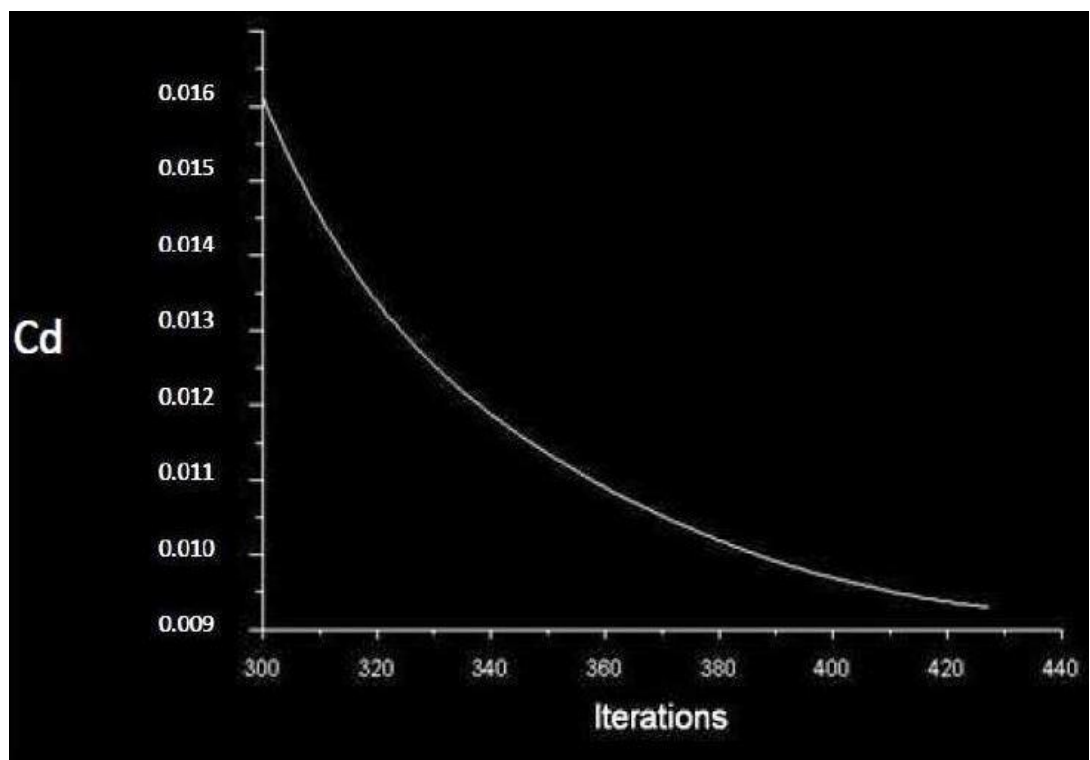

TCB6612

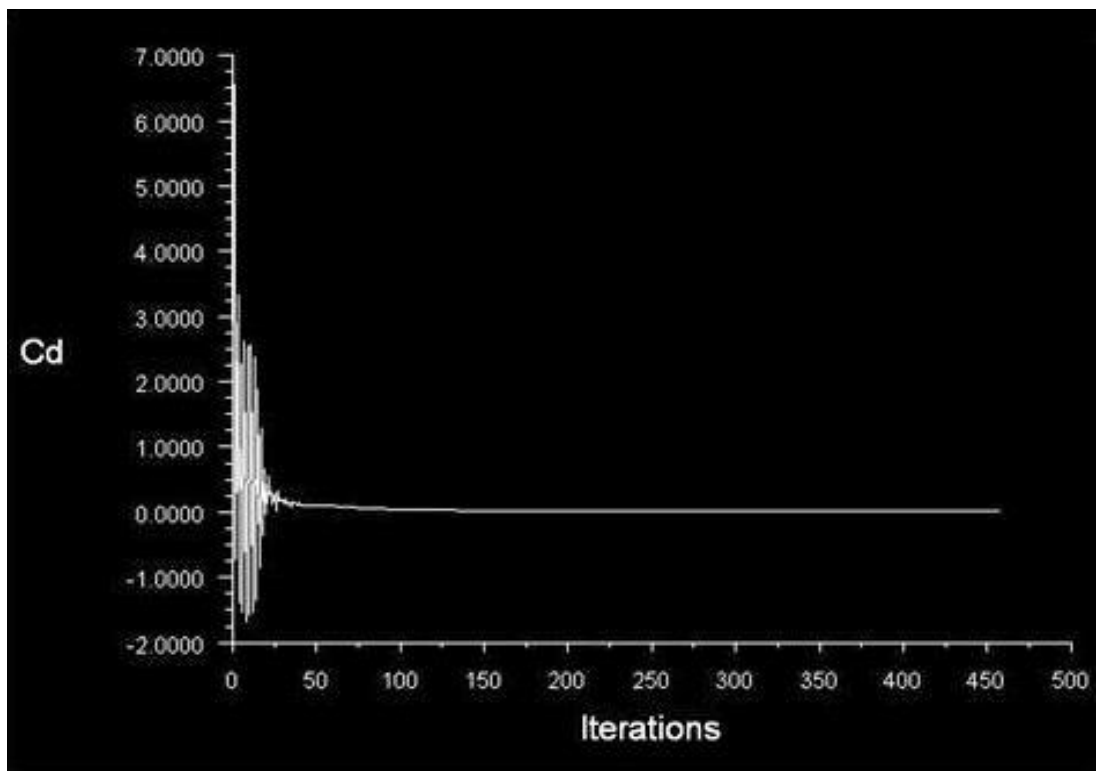

Figure (5): Drag Coefficient of NACA 4412 airfoil and TCB6612 airfoil. 


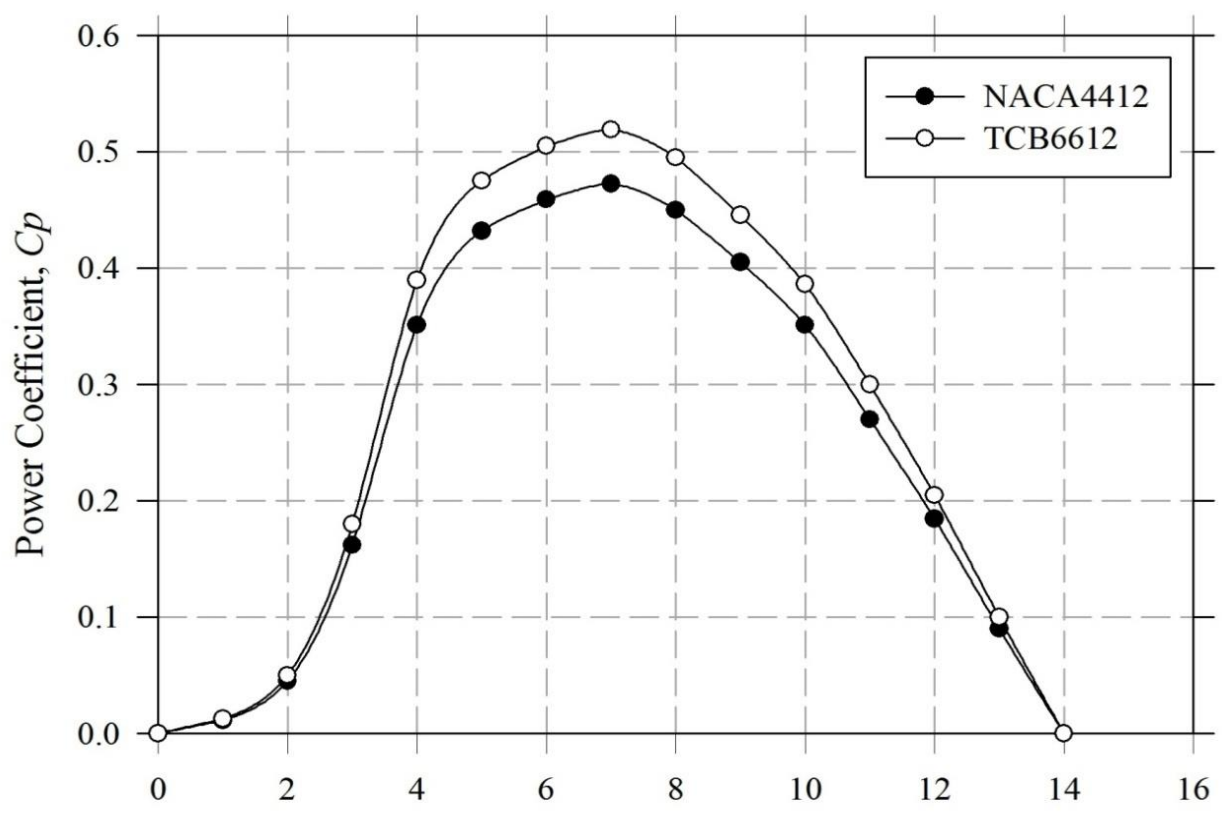

Tip Speed Ratio, $\lambda$

Figure (6): Influence of rotor blade thickness-to-chord on the rotor power coefficient for different airfoil.

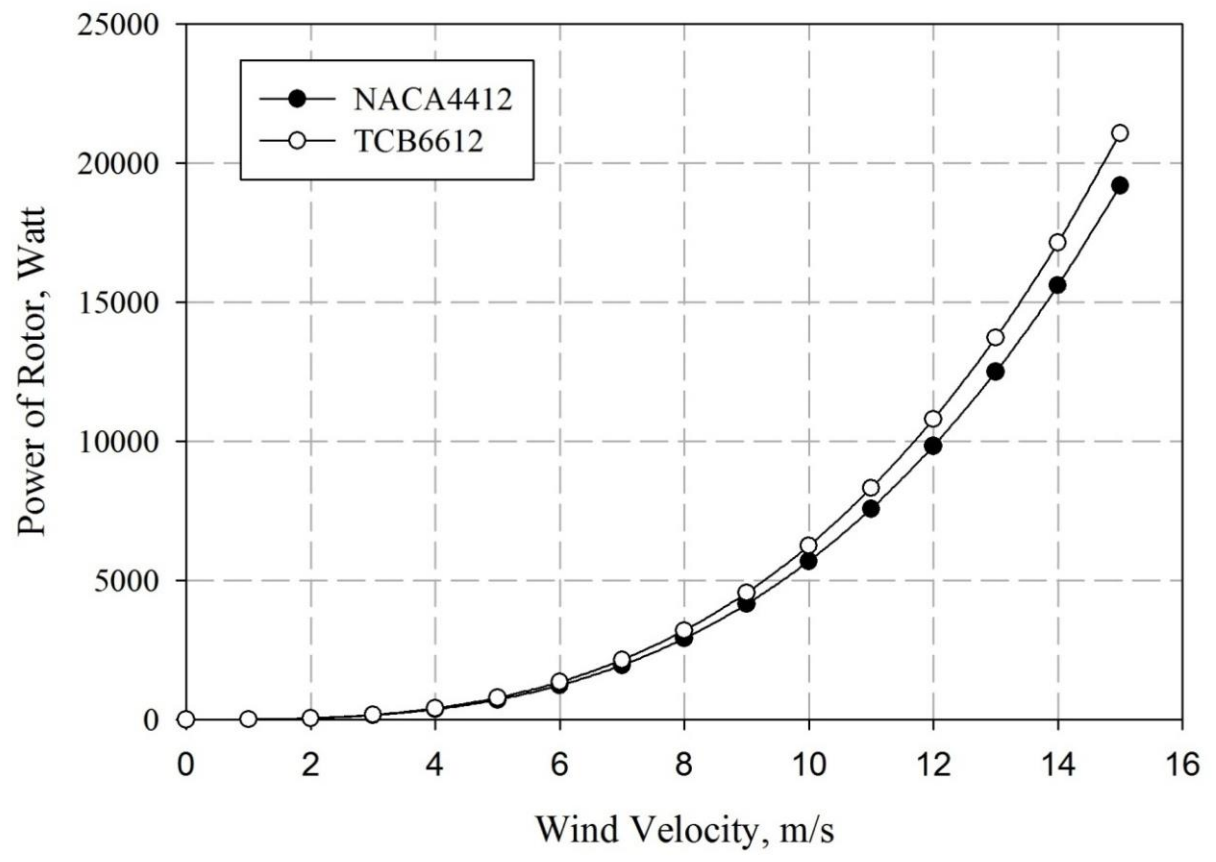

Figure (7): Power of rotor versus wind speed for different airfoil, calculated for rotor diameter $5 \mathrm{~m}$. 


\section{التحليل العددي لمطيار عنفة رياح

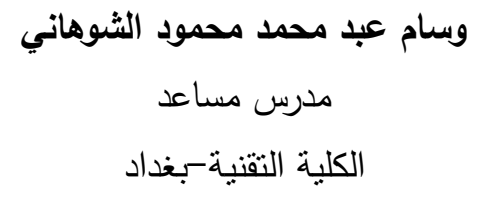

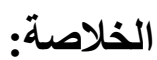

تعرض هذه الورقة التحليل العددي لمطيار جديد (TCB6612) ومقارنته مع مطيار قياسي (NACA4412) واستعمالهما في ريشة عنفة هوائية. الهدف الرئيسي من هذا العمل العمل هو تحسين الاداء الحركي الهوائي للمطيار وذللك من خلال تغيير الثكل الهندسي للمطيار من اجل زيادة الطاقة الاجمالية لعنفات الرياح. لانجاز هذا العمل تم استخدام برنامج كامبت GAMBIT و برنامج فلونت FLUENT، حيث استخدم برنامج كامبت لتكوين النمذجة للمطيار في حين

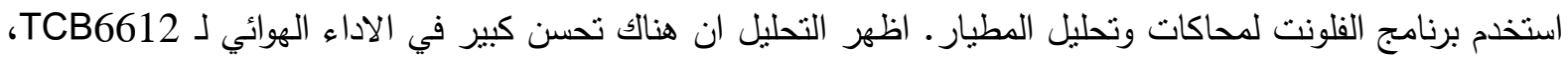

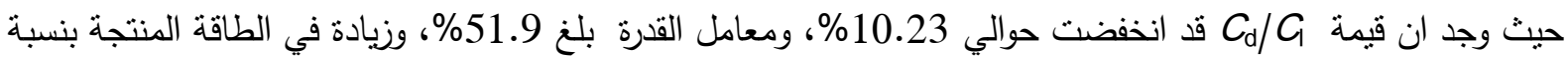
.\%9.8 